\title{
BMJ Open Aspirin and fracture risk: a systematic review and exploratory meta-analysis of observational studies
}

\author{
A L Barker, ${ }^{1,2}$ Sze-Ee Soh, ${ }^{1,3}$ Kerrie M Sanders, ${ }^{4,5}$ Julie Pasco, ${ }^{6}$ Sundeep Khosla, ${ }^{7}$ \\ Peter R Ebeling, ${ }^{8}$ Stephanie A Ward, ${ }^{1}$ Geeske Peeters, ${ }^{9}$ Jason Talevski, ${ }^{4,5}$ \\ Robert G Cumming, ${ }^{10}$ Ego Seeman, ${ }^{11,12}$ John J McNeil ${ }^{1}$
}

To cite: Barker AL, Soh S-E, Sanders KM, et al. Aspirin and fracture risk: a systematic review and exploratory metaanalysis of observational studies. BMJ Open 2020;10:e026876. doi:10.1136/ bmjopen-2018-026876

- Prepublication history and additional material for this paper are available online. To view these files, please visit the journal online (http://dx.doi. org/10.1136/bmjopen-2018026876).

Received 24 September 2018 Revised 16 0ctober 2019 Accepted 06 November 2019

Check for updates

(c) Author(s) (or their employer(s)) 2020. Re-use permitted under CC BY-NC. No commercial re-use. See rights and permissions. Published by BMJ.

For numbered affiliations see end of article.

Correspondence to

Dr A L Barker;

anna.barker@monash.edu

\section{ABSTRACT}

Objectives This review provides insights into the potential for aspirin to preserve bone mineral density (BMD) and reduce fracture risk, building knowledge of the risk-benefit profile of aspirin.

Methods We conducted a systematic review and exploratory meta-analysis of observational studies. Electronic searches of MEDLINE and Embase, and a manual search of bibliographies was undertaken for studies published to 28 March 2018. Studies were included if: participants were men or women aged $\geq 18$ years; the exposure of interest was aspirin; and relative risks, ORs and $95 \%$ Cls for the risk of fracture or difference (percentage or absolute) in BMD (measured by dual energy X-ray absorptiometry) between aspirin users and nonusers were presented. Risk of bias was assessed using the Joanna Briggs Institute Critical Appraisal Checklists for observational studies. Pooled ORs for any fracture and standardised mean differences (SMDs) for BMD outcomes were calculated using random-effects models.

Results Twelve studies met the inclusion criteria and were included in the meta-analysis. Aspirin use was associated with a $17 \%$ lower odds for any fracture (OR $0.83,95 \% \mathrm{Cl} 0.70$ to $0.99 ; \mathrm{I}^{2}=71 \%$; six studies; $\mathrm{n}=511390$ ). Aspirin was associated with a higher total hip BMD for women (SMD $0.03,95 \% \mathrm{Cl}-0.02$ to $0.07 ; \mathrm{l}^{2}=0 \%$; three studies; $\mathrm{n}=9686$ ) and men (SMD $0.06,95 \% \mathrm{Cl}-0.02$ to $0.13, I^{2}=0 \%$; two studies; $n=4137$ ) although these associations were not significant. Similar results were observed for lumbar spine BMD in women (SMD 0.03, $95 \% \mathrm{Cl}-0.03$ to $0.09 ; \mathrm{I}^{2}=34 \%$; four studies; $\mathrm{n}=11330$ ) and men (SMD 0.08; $95 \% \mathrm{Cl}-0.01$ to 0.18 ; one study; $\mathrm{n}=432$ ).

Conclusions While the benefits of reduced fracture risk and higher BMD from aspirin use may be modest for individuals, if confirmed in prospective controlled trials, they may confer a large population benefit given the common use of aspirin in older people.

\section{INTRODUCTION}

The anti-inflammatory effects of aspirin via prostaglandin inhibition have recently gained attention. Chronic low-grade inflammation contributes to age-related cardiovascular, neurological, respiratory and musculoskeletal conditions. ${ }^{1}$ Low-grade inflammation

\section{Strengths and limitations of this study}

- This systematic review extends prior observational studies by providing new evidence that suggests aspirin may be associated with reduced fracture risk and potentially higher bone mineral density.

- üThe observational studies included in this systematic review demonstrate an association between fracture risk and exposure to aspirin but firm conclusions about causation cannot be inferred without prospective controlled trials.

- üEven a small reduction in fracture risk forindividuals is likely to translate to large benefits at a population level given the common use of aspirin in older people most at risk of fractures.

is associated with increased bone loss and fracture risk. ${ }^{23}$ Prostaglandin, an important inflammatory mediator, is likely to have a key role in bone remodelling attributable to inflammation. ${ }^{4}$ Prostaglandin E2 stimulates bone resorption and formation and is produced largely from cyclooxygenase-2 induction. Prostaglandins acutely inhibit osteoclast function. ${ }^{5}$ However, their chronic effect is to stimulate bone resorption by increasing replication of osteoclast precursors, and differentiation to mature osteoclasts. Aspirin is an inhibitor of prostaglandin production and may influence the cellular basis of bone remodelling responsible for maintaining the material and structural strength of bone. ${ }^{1}$

These findings have led to growing interest in the potential for aspirin treatment to provide health benefits broader than cardiovascular, particularly in the prevention of age-related conditions. Osteoporosis-low bone mineral density (BMD) and structural deterioration of bone leading to increased risk of fractures-is the most common bone disease. ${ }^{6}$ More than 8.9 million fractures occur annually-equivalent to one fracture 
every $3 \mathrm{~s}^{7}$ The combined lifetime risk for hip, forearm and vertebral fractures requiring medical attention is around $40 \%$ - equivalent to the risk for cardiovascular disease. ${ }^{8}$ Despite the availability of several therapies, osteoporosis remains underdiagnosed and undertreated. ${ }^{9} \mathrm{Up}$ to $80 \%$ of those with at least one osteoporotic fracture do not receive treatment. ${ }^{9}$ As the ageing population grows worldwide, including in countries with under-resourced health systems, ${ }^{10-12}$ so will the demand for therapies that are low-cost, safe and readily available. ${ }^{13}$ If aspirin use reduces the risk of fracture, the public health impacts may be considerable because even a small benefit in averting or reducing age-related bone fragility may have a large impact at the community level.

There have been no randomised controlled trials (RCTs) reporting on the effects of aspirin treatment and fracture risk in human subjects. While there are increasing numbers of observational studies, findings are contradictory regarding associations between aspirin use and $\mathrm{BMD}^{14-17}$ and fracture risk. ${ }^{15-26} \mathrm{~A}$ review by Chin, ${ }^{27}$ concluded that aspirin may increase BMD, but its effect on fracture prevention is inconclusive. The limitations of this review were that it included only five observational studies and did not pool quantitative data via metaanalysis or other methods.

\section{Purpose of the current review}

Fractures are a growing personal and financial burden to individuals and the healthcare system. ${ }^{7}$ While there is some indication that aspirin use may be associated with improved BMD and reduced fracture risk, a meta-analysis would yield further insights. Conducting a meta-analysis where data are pooled across several studies can provide an opportunity to identify associations that may have gone undetected in individual studies. The aim of this systematic review was to resolve the controversy in findings from prior studies by conducting an exploratory meta-analysis to examine associations between aspirin use and fracture risk and BMD in adults. ${ }^{28}$

\section{MATERIALS AND METHODS}

\section{Search strategy and selection criteria}

We undertook a systematic review and meta-analysis in accordance with the Preferred Reporting Items for Systematic Reviews and Meta-Analyses guidelines. An electronic search for all literature (database inception to 28 March 2018) was performed using Ovid Medline and Embase. The search used MeSH terms ('aspirin' OR 'acetylsalicylic acid' OR 'paracetamol' OR 'nonsteroidal anti-inflammatory drugs') AND ('fracture' OR 'bone mineral density' OR 'osteoporosis'). In addition, a manual search of cited references from retrieved studies, recent systematic reviews, and meta-analyses was conducted (refer online supplementary material 1 for the list of search terms).

Two authors (JT and Sze-EeSoh) screened titles and abstracts to identify potentially relevant studies, and if a decision could not be made, the full text of the article was examined. Full length articles of selected abstracts were retrieved and assessed independently by two authors (JT and ALB). Studies were considered eligible for the meta-analysis if: (1) participants were men or women aged 18 years or older; (2) the exposure of interest was aspirin; and (3) relative risks, HR or OR and 95\% CIs for the risk of fracture or difference (percentage or absolute) in BMD (measured by dual energy X-ray absorptiometry (DXA)) between aspirin users and non-users were presented, or sufficient data were provided to enable these values to be calculated. We included studies that reported aspirin dose and duration either via self-report or identified through prescription histories. Studies were also included if an identifiable and separately analysed subgroup of people using aspirin was presented. Fracture outcomes included the number or rate of any fractures including non-vertebral fractures verified by imaging, while BMD outcomes included measures of bone mass of the whole body as well as at the total hip, proximal femur, femoral neck and spine or lumbar regions. When more than one article presented data from the same study population, the article with more complete reporting of data was selected to avoid double counting participants in the meta-analysis. ${ }^{29}$

Our aim was to include as many studies as possible in our meta-analysis, considering the limited number of published studies. Any study design was accepted including RCTs, other than single case design studies and systematic reviews. Grey literature such as $\mathrm{PhD}$ theses and conference abstracts were excluded to allow a reproducible search strategy. Only papers in English were considered.

\section{Assessment of risk of bias}

The risk of bias of included studies was assessed independently by two authors (JT and SES) using the suite of Joanna Briggs Institute (JBI) Critical Appraisal Checklists which have been approved by the JBI Scientific Committee following extensive peer review. ${ }^{30} 31$ The JBI critical appraisal tools are designed to assess the extent to which a study has addressed the possibility of bias in its design, conduct and analysis. ${ }^{30}$ These checklists assessed the sample characteristics, ascertainment of exposure, presence of confounding factors, measurement of outcomes, and the use of appropriate statistical techniques. Different criteria were used to appraise methodological quality depending on the study design to minimise bias and improve reliability of findings. ${ }^{32}$

For cohort studies, the criteria assessed whether groups were similar, if the follow-up time was sufficient to allow outcomes to occur, and loss to follow-up. For case-control studies, the criteria addressed issues related to the definition of cases and controls, selection of control and representativeness of cases, and the comparability of cases and controls. In cross-sectional studies, there was a focus on whether the inclusion criteria and setting of the study were clearly defined. Discrepancies in extracted data and 
quality appraisal were discussed and cross-referenced to the original article using a priori decision rules. If consensus could not be gained, agreement was obtained through discussions with a third person (ALB) as per the method described in the Cochrane Handbook for Systematic Reviews of Interventions. ${ }^{33}$

\section{Data extraction}

Data from included studies were independently extracted by two authors (JT and SES) using a customised electronic data extraction form that was piloted with a number of representative studies to ensure the content was appropriate. We extracted information from each study on first author; year and country of study; participant numbers and characteristics; study design; aspirin dose and duration; number of fractures (including site where available); BMD measures for each site (eg, whole body, proximal femur, total hip, femoral neck or lumbar spine); duration of follow-up; and covariates included for adjustment in the analysis.

\section{Statistical analysis}

In order to include studies with more than one treatment arm (eg, different aspirin doses) but only one control group, the effect estimate reported for each treatment group was included separately within the meta-analysis. However, the number of participants in the control group were divided equally between the comparisons as per the method described in the Cochrane Handbook for Systematic Review of Interventions. ${ }^{33}$ This process ensured that control participants were not counted more than once within the meta-analysis. ${ }^{33}$

Because of the various ways in which the authors reported data on changes in BMD and also wanting to maximise the number of studies and outcomes that could be included in our analysis, we used the standardised mean difference (SMD) approach ${ }^{33}$ as our summary statistic as opposed to the mean difference (MD) approach. The SMD yields a more conservative estimate than the MD, however, this was considered appropriate given the broad inclusion criteria of this review (which is likely to yield heterogeneity) and exploratory nature of the analysis where we wanted to minimise the likelihood of a type I error (false positive result). This approach allowed a direct comparison of associations across trials that reported either absolute or relative changes in BMD. For each study, the SMD was calculated as follows:

$$
\mathrm{SMD}=\frac{\text { mean }_{\text {aspirin }}-\text { mean }_{\text {non-aspirin }}}{\mathrm{SD}_{\text {pooled }}}\left(1-\frac{3}{4\left(N_{\text {total }}\right)-9}\right)
$$

The MD between aspirin and non-aspirin users was divided by the SD of the difference in BMD for all participants pooled across both treatment groups, and adjusted for small sample bias. ${ }^{34}$ The SE for the SMD was then calculated using the following formula:

$$
\mathrm{SE}\{\mathrm{SMD}\}=\sqrt{\frac{N_{\text {total }}}{\left(n_{\text {aspirin }}\right)\left(n_{\text {non-aspirin }}\right)}+\frac{\mathrm{SMD}^{2}}{2\left(N_{\text {total }}-3.94\right)}}
$$

If studies lacked SD estimates but provided a SE or CI that related to the MD, we estimated SDs using the following methods ${ }^{33}$ :

1. From SE to SD: the following formula was used: $\mathrm{SD}=\mathrm{SE} \times \sqrt{\mathrm{N}}$.

2. From $95 \%$ CI to SE: $\mathrm{SE}=\frac{\text { (upper limit-lower limit) }}{3.92}$.

The OR and 95\% CI (if available) was used to describe the association between aspirin use and fracture risk. Effect estimates were manually calculated when needed. Unless otherwise stated, we used the most adjusted risk estimate from each study.

It is known that results may vary systematically with observational study designs. ${ }^{35}$ As such, for each metaanalysis we performed a subgroup analysis based on study design to explore this. If no significant subgroup differences were identified, study designs were pooled in onemeta-analysis. The meta-analysis included subgroupings for aspirin doses (low dose $(\leq 150 \mathrm{mg} /$ day), high dose $(>150 \mathrm{mg} /$ day) and not reported) and sex in relation to fracture risk and BMD. As sex is an important effect modifier of BMD, results were reported separately for men and women. Sensitivity analyses were also performed by removing each individual study from the fracture and BMD meta-analysis, and removing studies based on study design to assess the robustness of our findings.

Additionally, the effect of aspirin on BMD or fracture risk was examined only when at least five studies reported on the outcome in order to ensure that we had sufficient power to detect a difference between the groups. ${ }^{36}$ We assessed heterogeneity between studies with the $\mathrm{I}^{2}$ statistic as a measure of the proportion of total variation in estimates that is due to heterogeneity. As heterogeneity was suspected in the data due to different study designs, study populations, follow-up duration and aspirin dose and duration, a random effects model was used. If the $\mathrm{I}^{2}$ value exceed $75 \%$ then a meta-analysis was not undertaken. ${ }^{37}$ An inverse variance method was also used to weight each estimate. All analyses were conducted with the use of Review Manager, V.5.0 (Revman, The Cochrane Collaboration; Oxford, UK) which allowed estimates and their SE to be entered directly using the 'Generic Inverse Variance' outcome to facilitate the analysis of continuous and dichotomous outcome data from non-randomised studies. ${ }^{33} 38$

\section{Patient and public involvement}

There was no direct patient or public involvement in this review.

\section{RESULTS}

\section{Description of studies}

There were 655 articles identified, 12 were duplicates and 601 were excluded after reviewing the titles and abstracts, leaving 46 articles. An additional four articles were found from reviewing references from articles obtained in full text. After full text review, a total of 14 articles were assessed as eligible for inclusion. However, 


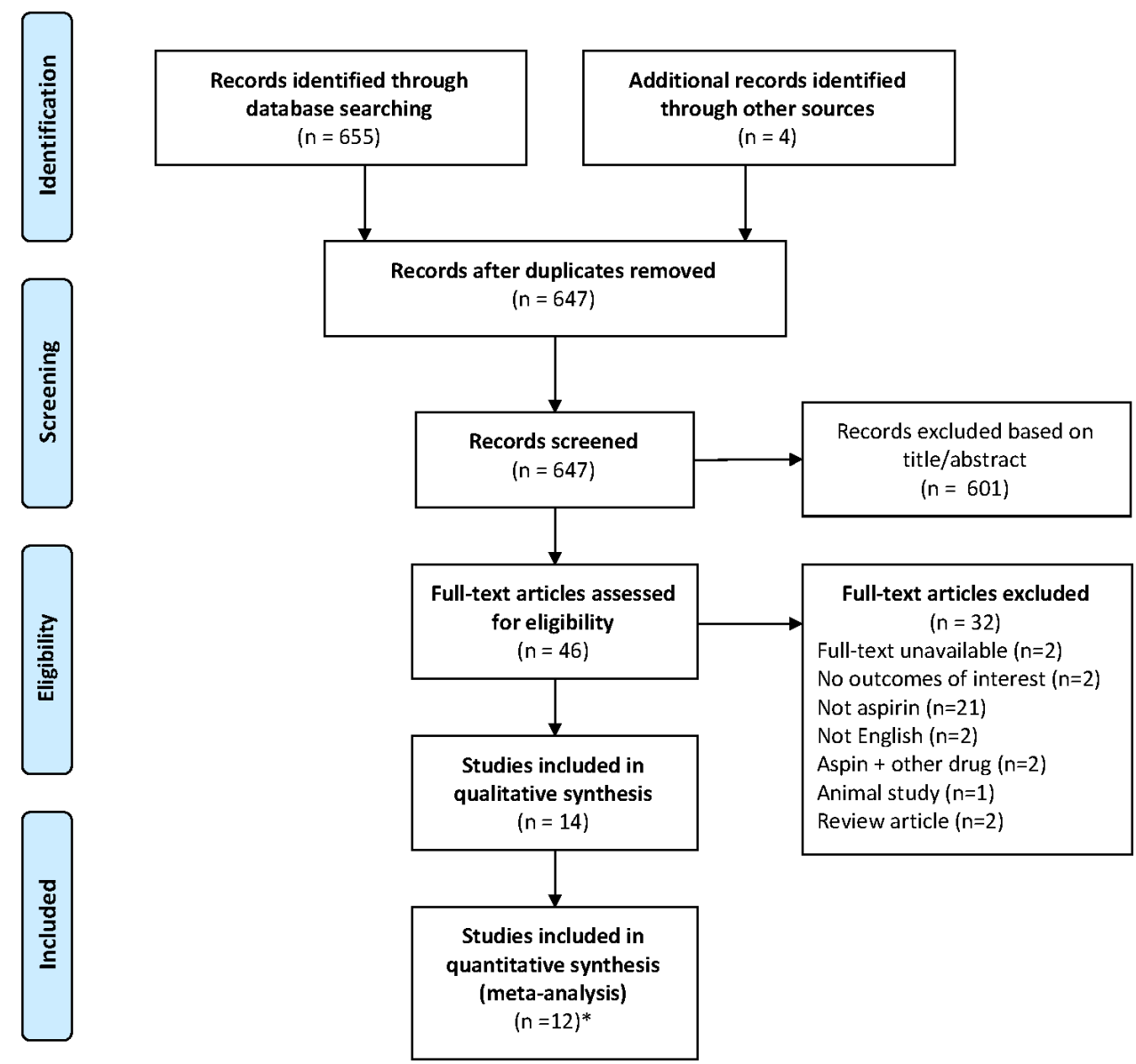

Figure 1 Preferred Reporting Items for Systematic Reviews and Meta-Analyses flowchart of study selection process.

only 12 studies were used as three ${ }^{192126}$ reported different outcomes on the same sample (figure 1). To avoid double counting, only data from Vestergaard $e t a l^{26}$ was used for the meta-analysis as it reported the most complete dataset. Of the 12 unique studies, three were prospective cohort studies, ${ }^{1518}{ }^{22}$ three were case-control studies, ${ }^{20} 2526$ and six were cross-sectional studies ${ }^{141617232439}$ (table 1). Four studies reported fracture outcomes only, ${ }_{18} 202526$ six studies reported BMD outcomes only ${ }^{1416232439}$ and the remaining four studies reported both fracture and BMD outcomes $^{1522}$ (online supplementary materials 1 and 2 ). We were unable to identify any RCTs of aspirin that included data on fracture or BMD outcomes.

\section{Risk of bias in included studies}

The risk of bias assessment is reported in table 2. The risk of bias was considered low for the three cohort studies with respect to the exposure, identifying and dealing with confounders, measuring outcomes, having sufficient follow-up time and using appropriate statistical analysis. Measurement of fracture and BMD outcomes were considered reliable and valid. Fractures were verified using radiological reports or obtained using the International Classification of Diseases 10 codes (online supplementary material 2), while all BMD outcomes were measured using DXA scans (online supplementary material 3). In contrast, reasons for loss of follow-up were not well documented, with only one ${ }^{18}$ describing strategies to address incomplete follow-up. For the case-control studies, the risk of bias was low for most studies ${ }^{192} 2526$ except for one ${ }^{20}$ which did not provide sufficient information regarding the cases and controls, as well as how exposure to aspirin was measured. The risk of bias for identifying confounders, measuring outcomes and using appropriate statistical analysis was low for all cross-sectional studies. However, inclusion criteria, study subjects, and measurement of exposure were poorly defined in a number of studies. ${ }^{14} 162339$

\section{Meta-analysis}

Effect estimates (ie, ORs) for the association between aspirin use and fracture risk were manually calculated for two studies. ${ }^{20} 25$ The MD in BMD outcomes were reported by three studies, ${ }^{222439}$ with the remaining studies reporting percentage difference in BMD. ${ }^{14-1723}$ Using equations (1) and (2), the SMD and SE for the SMD was calculated for each study and used in the meta-analysis.

No significant differences were identified when we performed a subgroup analysis based on study design (figure 2). Thus, data from included studies were pooled into one meta-analysis for fracture and BMD outcomes. Data pooled from six studies that included 511390 people indicated aspirin was associated with a $17 \%$ lower odds of any fracture (OR $0.83,95 \%$ CI 0.70 to 0.99 ; $\mathrm{I}^{2}=70 \%$; figure 3 ). There was no significant difference in 


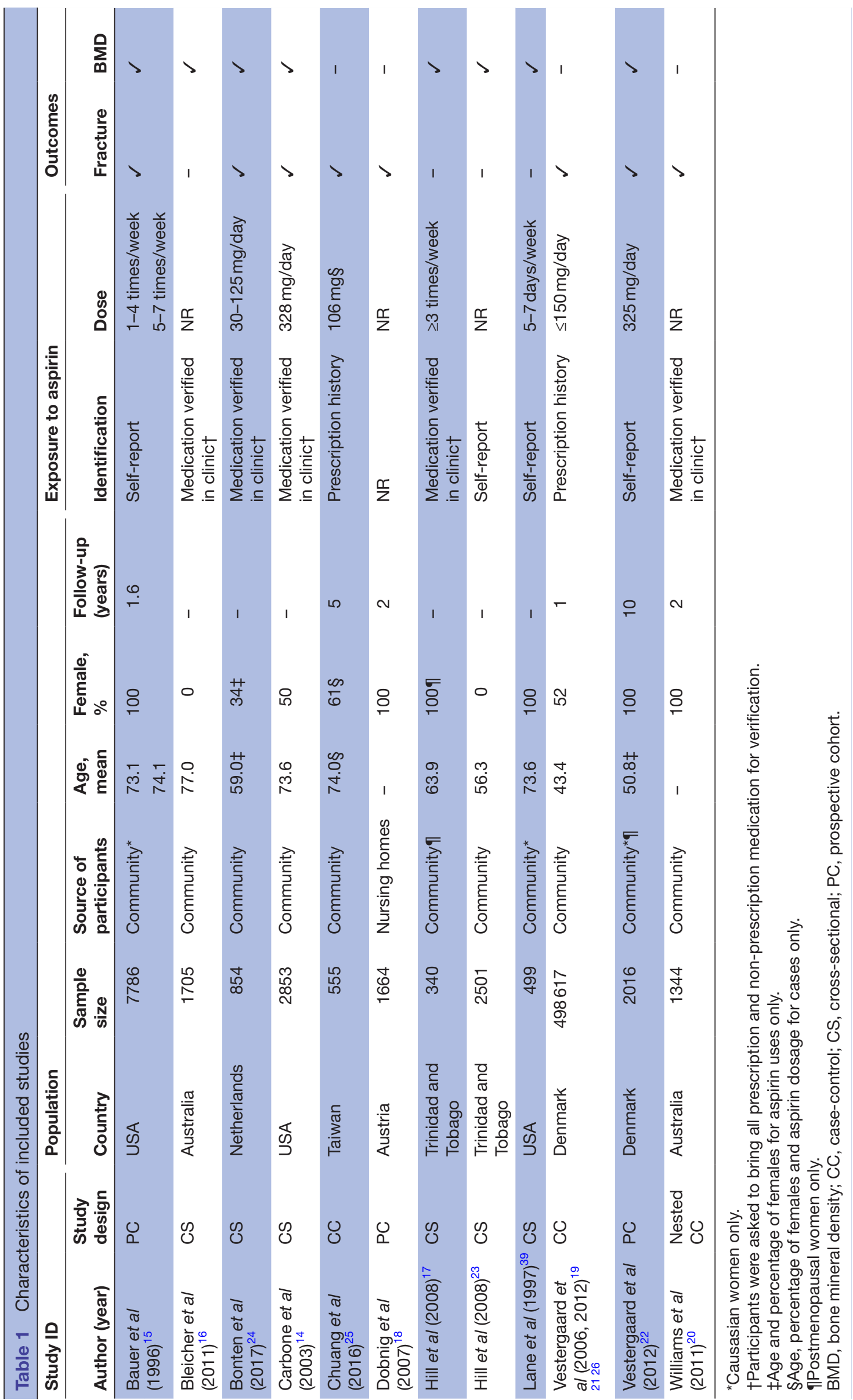




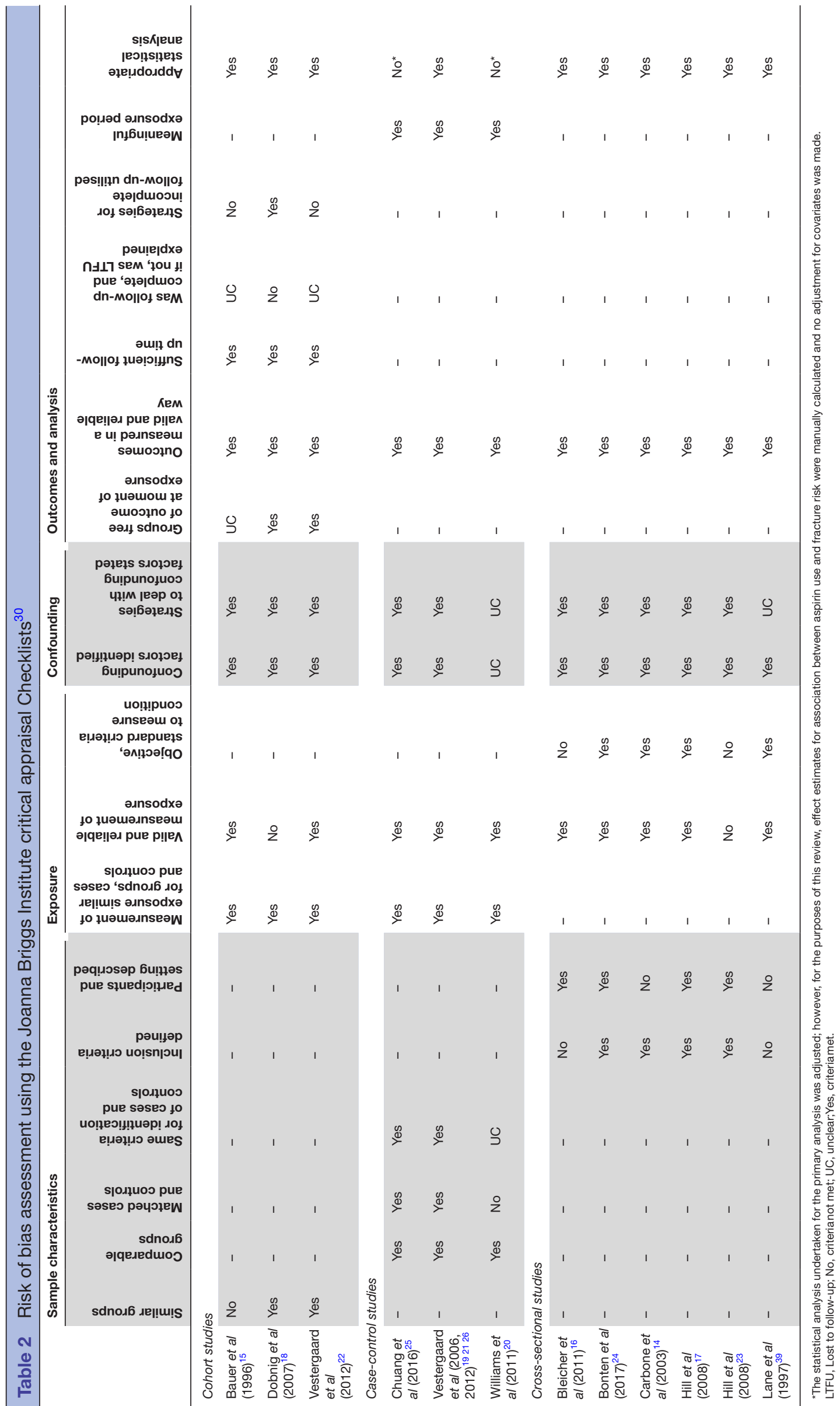




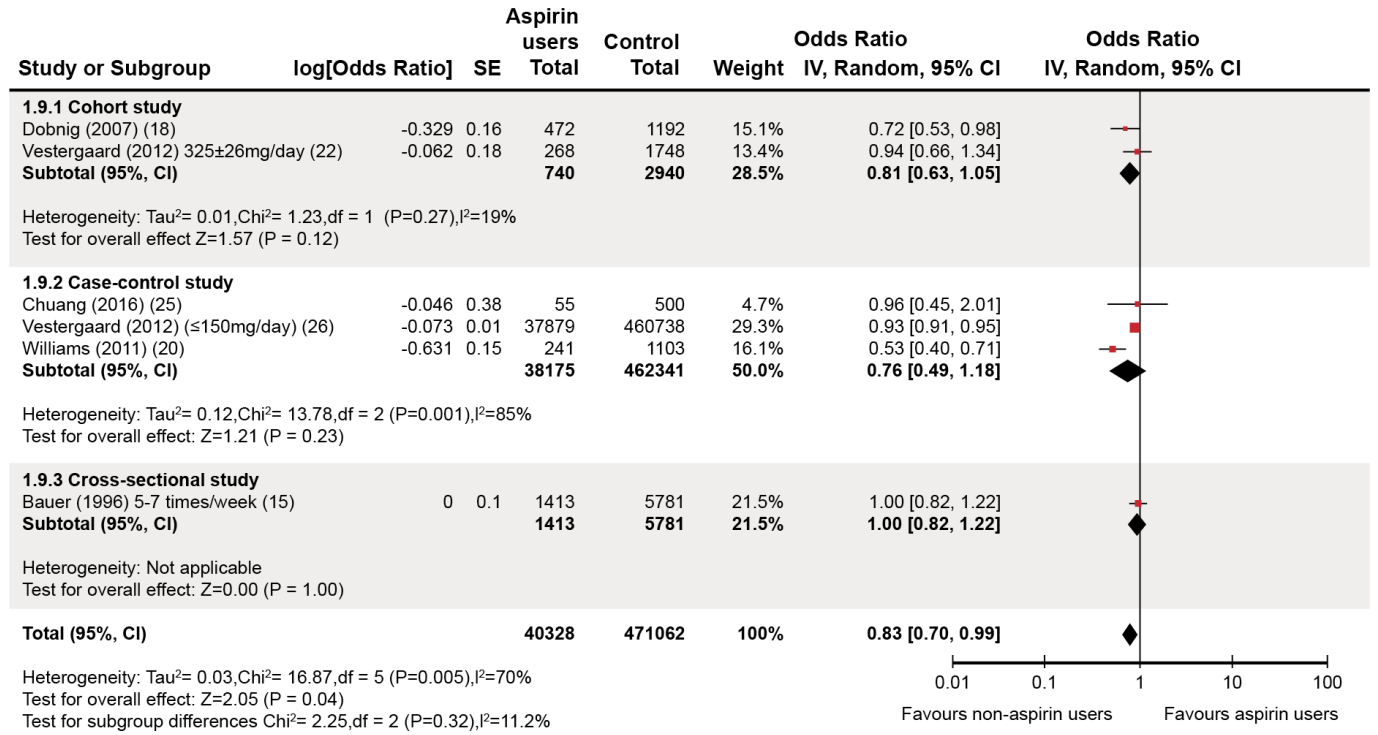

B

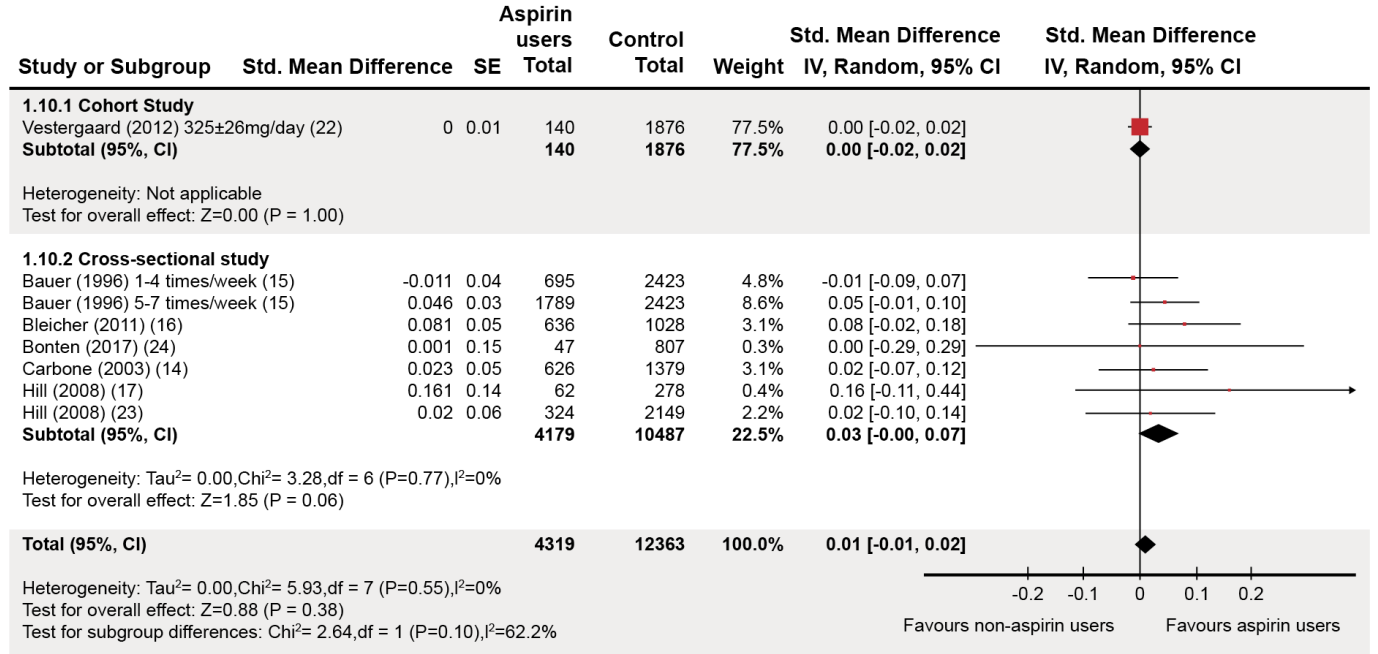

C

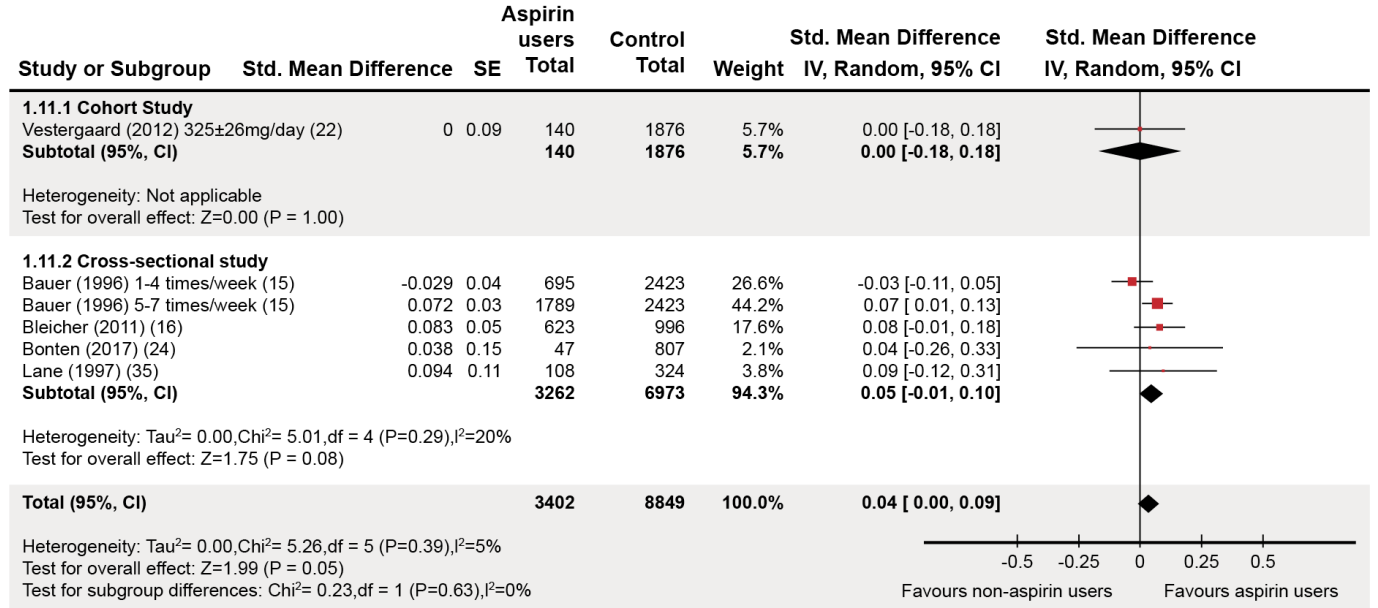

Figure 2 Meta-analysis of the association by study design of the association between aspirin use and (A) risk of any fracture (adjusted OR); (B) hip bone mineral density; and (C) lumbar spine bone mineral density. 


\begin{tabular}{|c|c|c|c|c|c|c|c|c|}
\hline Study or Subgroup & Ratio] & $\begin{array}{r}A \\
S E\end{array}$ & $\begin{array}{r}\text { Ispirin } \\
\text { users } \\
\text { Total }\end{array}$ & $\begin{array}{r}\text { Non-aspirin } \\
\text { users } \\
\text { Total }\end{array}$ & Weight & $\begin{array}{c}\text { Odds Ratio } \\
\text { IV, Random, } 95 \% \text { CI }\end{array}$ & $\begin{array}{c}\text { Odds Ratio } \\
\text { IV, Random, } 95 \% \mathrm{CI}\end{array}$ & \\
\hline $\begin{array}{l}\text { 1.1.1 Low dose aspirin ( } \leq 150 \mathrm{mg} / \text { day) } \\
\text { Chuang }(2016)(25) \\
\text { Vestergaard }(2012)(\leq 150 \mathrm{mg} / \text { day })(26) \\
\text { Subtotal }(95 \%, \mathrm{Cl}) \\
\text { Heterogeneity: } \text { Tau }^{2}=0.00, \mathrm{Chi}^{2}=0.01, \mathrm{df}=1 \\
\text { Test for overall effect: } Z=7.30(P<0.00001)\end{array}$ & $\begin{array}{r}-0.046 \\
-0.073 \\
(P=0.94), \mid\end{array}$ & $\begin{array}{l}0.38 \\
0.01 \\
\left.\right|^{2}=0 \%\end{array}$ & $\begin{array}{r}55 \\
37879 \\
\mathbf{3 7 9 3 4}\end{array}$ & $\begin{array}{r}500 \\
460738 \\
461238\end{array}$ & $\begin{array}{r}4.7 \% \\
29.3 \% \\
33.9 \%\end{array}$ & $\begin{array}{l}0.96[0.45,2.01] \\
0.93[0.91,0.95] \\
0.93[0.91,0.95]\end{array}$ & 1 & \\
\hline $\begin{array}{l}\text { 1.1.2 High dose aspirin (>150mg/day) } \\
\text { Vestergaard }(2012) 325 \pm 26 \mathrm{mg} / \text { day }(22) \\
\text { Subtotal }(95 \%, \mathrm{Cl}) \\
\text { Heterogeneity: Not applicable } \\
\text { Test for overall effect: } Z=0.34(P=0.73)\end{array}$ & -0.062 & 0.18 & $\begin{array}{l}268 \\
268\end{array}$ & $\begin{array}{l}1748 \\
1748\end{array}$ & $\begin{array}{l}13.4 \% \\
13.4 \%\end{array}$ & $\begin{array}{l}0.94[0.66,1.34] \\
0.94[0.66,1.34]\end{array}$ & & \\
\hline $\begin{array}{l}\text { 1.1.3 Dose not reported (mg/day) } \\
\text { Bauer }(1996) 5-7 \text { times/week (15) } \\
\text { Dobnig }(2007)(18) \\
\text { Williams }(2011)(20) \\
\text { Subtotal }(95 \%, \mathrm{Cl}) \\
\text { Heterogeneity: } \text { Tau }^{2}=0.10, \mathrm{Chi}^{2}=12.81, \mathrm{df}=2 \\
\text { Test for overall effect: } Z=1.56(P=0.12)\end{array}$ & $\begin{array}{r}0 \\
-0.329 \\
-0.631 \\
(P=0.002\end{array}$ & $\begin{array}{l}0.1 \\
0.16 \\
0.15 \\
2), 1^{2}=84\end{array}$ & $\begin{array}{r}1413 \\
472 \\
241 \\
2126 \\
\end{array}$ & $\begin{array}{l}5781 \\
1192 \\
1103 \\
\mathbf{8 0 7 6}\end{array}$ & $\begin{array}{l}21.5 \% \\
15.1 \% \\
16.1 \% \\
\mathbf{5 2 . 7} \%\end{array}$ & $\begin{array}{l}1.00[0.82,1.22] \\
0.72[0.53,0.98] \\
0.53[0.40,0.71] \\
\mathbf{0 . 7 3}[\mathbf{0 . 5 0}, \mathbf{1 . 0 8}]\end{array}$ & - & \\
\hline Total $(95 \%, \mathrm{Cl})$ & & & 40328 & 471062 & $100 \%$ & $0.83[0.70,0.99]$ & & \\
\hline $\begin{array}{l}\text { Heterogeneity: } \mathrm{Tau}^{2}=0.03, \mathrm{Chi}^{2}=16.87, \mathrm{df}=5 \\
\text { Test for overall effect: } \mathrm{Z=2.05}(\mathrm{P}=0.04) \\
\text { Test for subgroup differences: } \mathrm{Chi}^{2}=1.41 \mathrm{df}=\end{array}$ & $\begin{aligned} & (P=0.005 \\
= & 2(P=0.4\end{aligned}$ & 5), $1^{2}=7$ & & & & $\begin{array}{ll}0.1 & 0.2 \\
\text { Favours aspi }\end{array}$ & 12 & $\begin{array}{cc}5 & 10 \\
\text {-aspirin users }\end{array}$ \\
\hline
\end{tabular}

Figure 3 Meta-analysis of the association between aspirin use and risk of any fracture (adjusted OR) by aspirin dosage.

associations across dose subgroups (figure 3). A subgroup analysis on studies that included only women was not undertaken as considerable heterogeneity was observed with an $\mathrm{I}^{2}$ value of $78 \%$. There were no studies that examined risk of fractures only in men.

Aspirin was associated with a higher total hip BMD for women (SMD $0.03,95 \%$ CI -0.02 to $0.07 ; \mathrm{I}^{2}=0 \%$; three studies; $\mathrm{n}=9686$; figure $4 \mathrm{~A}$ ) and men (SMD $0.06,95 \% \mathrm{CI}$ -0.02 to $0.13, \mathrm{I}^{2}=0 \%$; two studies; $\mathrm{n}=4137$; figure $4 \mathrm{~A}$ ) although these associations were not significant. There were also no significant differences in associations across dose (figure 4B). Similar results were observed for lumbar spine BMD in women (SMD 0.03, 95\% CI -0.03 to 0.09 ; $\mathrm{I}^{2}=34 \%$; four studies; $\mathrm{n}=11330$; figure $4 \mathrm{C}$ ) and men (SMD $0.08,95 \%$ CI -0.01 to 0.18 ; one study; $n=432$; figure $4 \mathrm{C}$ ).

Sensitivity analysis was performed whereby each study was removed from the fracture and BMD meta-analysis. The direction of association remained when individual studies were removed but significance often changed. For example, when the Williams et $a l^{20}$ study was removed from the analysis, aspirin was associated with a $7 \%$ lower odds of any fracture (OR $0.93,95 \%$ CI 0.91 to 0.95 ). When we removed the Bauer et al ${ }^{15}$ study from the lumbar spine BMD meta-analysis, aspirin use was associated with higher spine BMD in women (SMD 0.04, 95\% CI -0.10 to 0.17 ) and men (SMD $0.08,95 \%$ CI -0.01 to 0.18 ). Similar results were obtained when we removed individual studies based on type of design.

No meta-analyses were undertaken for femoral neck or total body BMD as there were too few studies. Only four studies reported on femoral neck BMD ${ }^{16} 172223$ and two reported on total body BMD with conflicting results. ${ }^{14} 22$ Two studies reported no association between aspirin and femoral neck BMD, ${ }^{22} 23$ while two reported a higher femoral neck BMD in aspirin users compared with non-users. ${ }^{16}{ }^{17}$ Likewise, only one of the studies that reported on total body BMD reported a higher total BMD in aspirin users compared with non-users. ${ }^{14}$

\section{DISCUSSION}

\section{Main findings}

Aspirin is one of the most commonly used medications worldwide and has the potential to benefit and/ or prevent many chronic diseases. This review extends previous reviews of aspirin and bone ${ }^{27}$ by including additional studies ${ }^{16-18} 20^{23-25} 40$ and an exploratory metaanalysis. While firm conclusions about causation cannot be inferred, and nor was this the intent of our exploratory review, our findings suggest that aspirin use was associated with a lower risk of any fracture and potentially higher BMD at the spine and hip. These findings are consistent with preclinical and animal studies. ${ }^{27}$ While the reduction in fracture risk was small, given the widespread use of aspirin and the high prevalence of undetected low bone density, even small reductions in fracture risk may yield considerable benefits at a population level. Even though we do not expect that aspirin would be considered as a primary fracture prevention therapy, this study builds on the knowledge of the potential broader benefits of aspirin therapy for those taking it for cardiovascular indications.

The consistent findings of reduced risk of fracture across studies included in this review is encouraging. It is important to keep in mind that studies were quite diverse in design, populations included, data collection methods and follow-up periods and we did observe high heterogeneity especially for fracture risk. While we need to interpret this finding with some caution, there appeared to be a consistent indication that aspirin use is associated with positive bone outcomes. While our findings suggest that dose and 
A

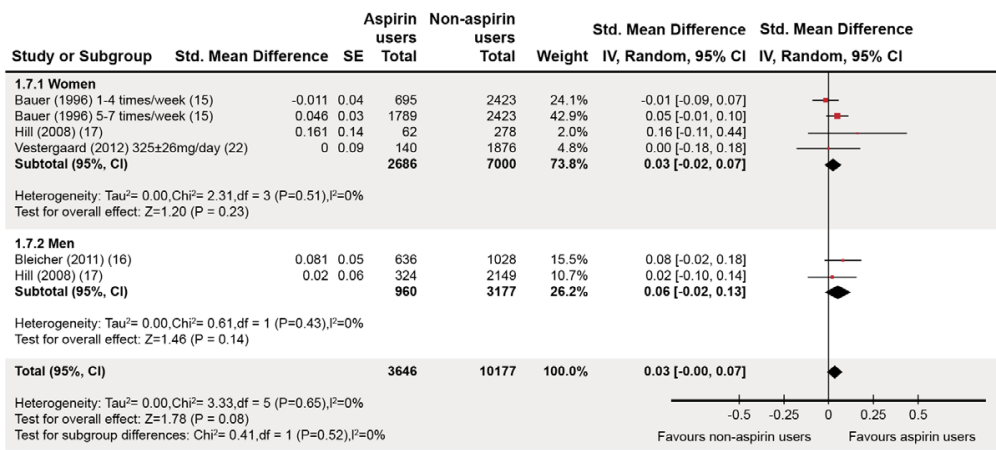

B

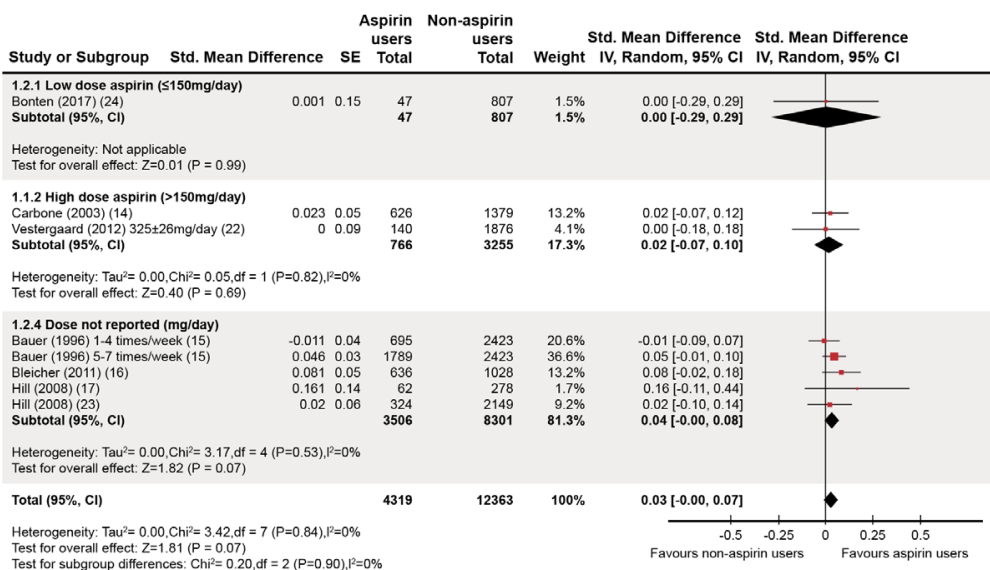

C

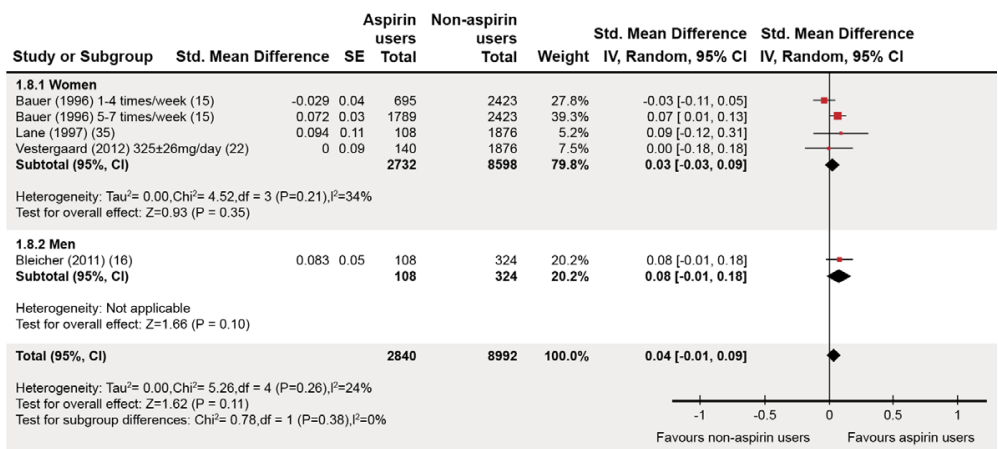

D

\begin{tabular}{|c|c|c|c|c|c|c|c|c|}
\hline Study or Subgroup & \multicolumn{2}{|c|}{ Std. Mean Difference } & \multicolumn{2}{|c|}{$\begin{array}{r}\text { Aspirin } \\
\text { users } \\
\text { SE Total }\end{array}$} & $\begin{array}{r}\text { Non-aspirin } \\
\text { users } \\
\text { Total }\end{array}$ & \multicolumn{2}{|c|}{$\begin{array}{r}\text { Std. Mean Difference } \\
\text { Weight } \\
\text { IV, Random, } 95 \% \mathrm{Cl}\end{array}$} & $\begin{array}{l}\text { Std. Mean Difference } \\
\text { IV, Random, } 95 \% \mathrm{Cl}\end{array}$ \\
\hline \multicolumn{2}{|c|}{$\begin{array}{l}1.2 .1 \text { Low dose aspirin (s150mg/day) } \\
\text { Bonten }(2017)(24) \\
\text { Subtotal }(95 \%, \mathrm{Cl})\end{array}$} & 0.038 & & $\begin{array}{l}47 \\
47\end{array}$ & $\begin{array}{l}807 \\
807\end{array}$ & $\begin{array}{l}2.1 \% \\
2.1 \%\end{array}$ & $\begin{array}{l}0.04[-0.26,0.33] \\
0.04[-0.26,0.33]\end{array}$ & \\
\hline \multicolumn{9}{|c|}{$\begin{array}{l}\text { Heterogeneity Not applicable } \\
\text { Test for overall effect: } Z=0.25(P=0.80)\end{array}$} \\
\hline \multicolumn{3}{|c|}{$\begin{array}{l}1.2 .2 \text { High dose aspirin (>150mg/day) } \\
\text { Vestergaard }(2012) 325 \pm 26 \mathrm{mg} / \mathrm{day}(22) \\
\text { Subtotal }(95 \%, \mathrm{Cl})\end{array}$} & 0.09 & $\begin{array}{l}140 \\
140\end{array}$ & $\begin{array}{l}1876 \\
1876\end{array}$ & $\begin{array}{l}5.7 \% \\
5.7 \%\end{array}$ & $\begin{array}{l}0.00[-0.18,0.18] \\
0.00[-0.18,0.18]\end{array}$ & \\
\hline \multicolumn{9}{|c|}{$\begin{array}{l}\text { Heterogeneity: Not applicable } \\
\text { Test for overall effect: } Z=0.00(P=1.00)\end{array}$} \\
\hline \multicolumn{2}{|c|}{ 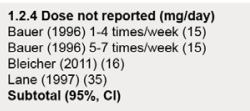 } & $\begin{array}{l}-0.029 \\
0.072 \\
0.083 \\
0.094\end{array}$ & $\begin{array}{l}0.04 \\
0.03 \\
0.05 \\
0.11\end{array}$ & $\begin{array}{r}695 \\
1789 \\
623 \\
108 \\
3215\end{array}$ & $\begin{array}{r}2423 \\
2423 \\
926 \\
324 \\
6166\end{array}$ & $\begin{array}{l}26.6 \% \\
44.2 \% \\
17.6 \% \\
3.8 \% \\
92.3 \%\end{array}$ & $\begin{array}{l}-0.03[-0.11,0.05] \\
0.07[0.01,0.13] \\
0.08[-0.01,0.18] \\
0.09-[-12.0 .31] \\
0.05[-0.01,0.10]\end{array}$ & $=$ \\
\hline \multicolumn{9}{|c|}{$\begin{array}{l}\text { Heterogeneity: } \text { Tau}^{2}=0.00, \mathrm{Ch}^{2}=5.00, \mathrm{df}=3(\mathrm{P}=0.17),{ }^{\mathrm{P}}=40 \% \\
\text { Test for overall effect: } Z=1.50(P=0.13)\end{array}$} \\
\hline \multicolumn{3}{|l|}{ Total $(95 \%, \mathrm{Cl})$} & & 3402 & 8849 & $100 \%$ & $0.04[0.00,0.09]$ & $b$ \\
\hline
\end{tabular}

Figure 4 Meta-analysis of the association between aspirin use and bone mineral density in the (A) hip by sex; (B) hip by aspirin dosage; (C) lumbar spine by sex; and (D) lumbar spine by aspirin dosage. 
sex subgroups do not influence bone outcomes, these subgroup analyses were likely underpowered. Only eight of the 14 publications reported aspirin dosage in terms of frequency and dose. There were also no studies that reported on aspirin use and fracture outcomes in men only. In contrast, six of the studies were conducted in women only. ${ }^{151718202239}$ Future studies should aim to collect and report findings for different aspirin doses and sex to enable dose-and-or sex related effects (if any) to be ascertained.

When low-dose aspirin use is recommended for prevention of cardiovascular disease by a healthcare professional, nine of 10 adults will follow the recommendation. ${ }^{41}$ This suggests the drug is broadly accepted by patients as a treatment regime. The findings of this review build on the existing evidence that supports the role of aspirin in the prevention of conditions including cancer ${ }^{42}$ and depression. ${ }^{43}$ As the population ages, increasing numbers of older people will be taking aspirin. Knowledge of the relative benefits and risks beyond cardiovascular in older individuals is critical to inform treatment decisions. If future RCTs provide evidence of positive effects on bone and fracture prevention, it will be reassuring for those taking aspirin for cardiovascular indications to know that the drug has additional positive health impacts beyond those for which its primary therapeutic effect was intended.

\section{Limitations}

Some caution is needed in interpreting the findings. The search strategy included full-text reports published in English and we may have missed studies in other languages. In addition, meta-analyses of observational studies are subject to the same biases and confounding in the original studies such as confounding by indication and unmeasured factors, self-report of aspirin use, and survival bias. We minimised these limitations by: (1) developing explicit and broad criteria that focused on extracting the best available evidence ${ }^{44}$; ; (2) utilising a broad search strategy to ensure that all relevant literature was included ${ }^{45}$; and (3) exploring sources of heterogeneity by conducting subgroup analyses, none of which revealed any significant differences in findings. Importantly, several studies reported aspirin users and non-users differed at baseline in risk factors for fracture. These included: age ${ }^{15} ; \operatorname{sex}^{14} ; \operatorname{race}^{14}$; weight $^{1540}$; oestrogen therapy ${ }^{14}{ }^{15}$; prescription of medications known to increase falls risk ${ }^{19} 2126$; higher levels of comorbidity $^{192126}$; number of prior fractures ${ }^{192126}$; and existing diagnosis of osteoporosis, osteoarthritis or rheumatoid arthritis. ${ }^{141540}$ While analyses often adjusted for these factors, the risk that groups were systematically different in factors neither measured nor adjusted for, remains high. For example, no study reported adjustment for physical activity. Aspirin use could also be a marker for an unmeasured confounder. This confounding by indication, and resulting imbalance in the underlying risk profile between aspirin users and non-users, may have biassed results. Further, data on confounding variables were often self-reported. ${ }^{15}$ Most studies were subject to recall bias particularly with respect to use of aspirin. All studies relied on participant self-reporting of current and prior aspirin use over long periods of time (range, 1-10 years), which is known to over-estimate actual drug use, ${ }^{46}$ with two studies being completed retrospectively. This is likely to increase the potential effect of aspirin on fracture risk and BMD. Finally, none of the studies reported fracture or BMD results separately for first or subsequent fractures. The cause of fractures (eg, trauma) were also not reported by included studies. As such, we are unable to determine whether the potential protective association of aspirin is for primary or secondary prevention. This would be valuable to explore in future research.

\section{Implications}

The WHO has identified fracture prevention as a public health priority. ${ }^{47}$ By the year 2040, the number of people at high risk of sustaining a fracture will double to 319 million. ${ }^{48}$ The evidence presented in this review provides a window into the potential for aspirin to be a novel therapy for fracture prevention. While causation cannot be inferred from our review findings, we have provided a basis to inform future research including RCTs that aim to examine the effect of aspirin on fracture risk. Given that aspirin use is not without risk any potential skeletal benefits must be considered in the broader context of therapeutic risk. Studies in older people report long-term use of aspirin is associated with increased risk of major bleeding ${ }^{49}{ }^{50}$ including haemorrhagic stroke. ${ }^{51}$ Currently there is an absence of RCT data in those aged 70 years and older who have an increased susceptibility to adverse drug effects due to impaired hepatic and renal function, polypharmacy and comorbidity. Thus, there is a need for future research, particularly RCTs in older people to focus on assessing data on multiple end-points (such as cardiovascular, bleeding, fractures and mortality) in the one population to provide accurate estimates of the relative benefits and risks of using aspirin.

\section{Author affiliations}

${ }^{1}$ Department of Epidemiology and Preventive Medicine, Monash University, Melbourne, Victoria, Australia

${ }^{2}$ Member Health, Medibank Private, Melbourne, Victoria, Australia ${ }^{3}$ Department of Physiotherapy, Monash University, Melbourne, Victoria, Australia ${ }^{4}$ Department of Medicine-Western Health, University of Melbourne Faculty of VCA and MCM, Melbourne, Victoria, Australia

${ }^{5}$ Australian Institute for Musculoskeletal Science (AIMSS), The University of Melbourne and Western Health, Melbourne, Victoria, Australia

${ }^{6}$ Clinical and Biomedical Sciences: Barwon Health, The University of Melbourne, Geelong, Victoria, Australia

${ }^{7}$ Division of Endocrinology and Center on Aging, Rochester, Minnesota, USA ${ }^{8}$ Bone and Muscle Health Research Group, School of Clinical Sciences at Monash Health, Monash Medical Centre, Melbourne, Victoria, Australia

${ }^{9}$ Global Brain Health Institute, Trinity College Dublin, Dublin, Ireland

${ }^{10}$ School of Public Health, University of Sydney, Camperdown, New South Wales, Australia

${ }^{11}$ Endocrinology and Medicine, Austin Health, Heidelberg, Victoria, Australia

${ }^{12}$ Mary McKillip Institute of Healthy Aging, Australian Catholic University, Melbourne, Victoria, Australia

Acknowledgements The authors gratefully acknowledge the contribution of $\mathrm{Dr}$ Joanne McKenzie for her statistical advice. 
Contributors All authors provided substantial contribution to conception and design of the project; drafted and revised the article critically for important intellectual content; and approved the final manuscript. JT led the literature search, and completed the study selection, data extraction, and critical appraisal with SES. ALB and SES accept responsibility for the integrity of the data analyses. ALB led the drafting of all sections of the article in consultation with all of the coauthors. KMS, SAW, SK, RGC, ES, JP, GP, PRE and JJM provided substantial contributions to the background, critical appraisal of prior studies and interpretation of meta-analysis findings. SES provided substantial contribution to the methods section.

Funding This work was supported by an Australian National Health and Medical Research Council (NHMRC) Project Grant (project number: APP1067242). ALB was supported by a NHMRC Career Development Fellowship (1067236). JT was supported by a National Health and Medical Research Council (NHMRC) Postgraduate Scholarship (1151089)

Competing interests ALB, KS, JP, SK, PE, SAW, RGC, ES and JJM are the members of the investigator group for the ASPREE-Fracture substudy.

Patient consent for publication Not required.

Provenance and peer review Not commissioned; externally peer reviewed.

Data availability statement Data are available upon reasonable request.

Open access This is an open access article distributed in accordance with the Creative Commons Attribution Non Commercial (CC BY-NC 4.0) license, which permits others to distribute, remix, adapt, build upon this work non-commercially, and license their derivative works on different terms, provided the original work is properly cited, appropriate credit is given, any changes made indicated, and the use is non-commercial. See: http://creativecommons.org/licenses/by-nc/4.0/.

\section{REFERENCES}

1 Franceschi C, Campisi J. Chronic inflammation (inflammaging) and its potential contribution to age-associated diseases. J Gerontol A Biol Sci Med Sci 2014;69 Suppl 1:S4-9.

2 Lencel P, Magne D. Inflammaging: the driving force in osteoporosis? Med Hypotheses 2011;76:317-21.

3 Pasco JA, Seeman E, Henry MJ, et al. The population burden of fractures originates in women with osteopenia, not osteoporosis. Osteoporos Int 2006;17:1404-9.

4 Blackwell KA, Raisz LG, Pilbeam CC. Prostaglandins in bone: bad COP, good COP? Trends Endocrinol Metab 2010;21:294-301.

5 Raisz LG, Pilbeam CC, Fall PM. Prostaglandins: mechanisms of action and regulation of production in bone. Osteoporosis Int 1993;3:136-40

6 Cosman F, de Beur SJ, LeBoff MS, et al. Clinician's guide to prevention and treatment of osteoporosis. Osteoporos Int 2014;25:2359-81.

7 Pisani P, Renna MD, Conversano F, et al. Major osteoporotic fragility fractures: risk factor updates and societal impact. World J Orthop 2016;7:171-81.

8 Kanis JA. Diagnosis of osteoporosis and assessment of fracture risk. Lancet 2002;359:1929-36.

9 Nguyen TV, Center JR, Eisman JA. Osteoporosis: underrated, underdiagnosed and undertreated. Med J Aust 2004;180:S18-22.

10 Lloyd-Sherlock P. Population ageing in developed and developing regions: implications for health policy. Soc Sci Med 2000;51:887-95.

11 Pillay NK, Maharaj P. Population ageing in Africa. In: Aging and health in Africa. Springer, 2013: 11-51.

12 Mithal A, Bansal B, Kyer CS, et al. The Asia-Pacific regional auditepidemiology, costs, and burden of osteoporosis in India 2013: a report of international osteoporosis foundation. Indian $J$ Endocrinol Metab 2014;18:449-54.

13 Khatib R, McKee M, Shannon $\mathrm{H}$, et al. Availability and affordability of cardiovascular disease medicines and their effect on use in highincome, middle-income, and low-income countries: an analysis of the pure study data. Lancet 2016;387:61-9.

14 Carbone LD, Tylavsky FA, Cauley JA, et al. Association between bone mineral density and the use of nonsteroidal anti-inflammatory drugs and aspirin: impact of cyclooxygenase selectivity. J Bone Miner Res 2003;18:1795-802.

15 Bauer DC, Orwoll ES, Fox KM, et al. Aspirin and NSAID use in older women: effect on bone mineral density and fracture risk. study of osteoporotic fractures Research Group. J Bone Miner Res 1996;11:29-35

16 Bleicher K, Cumming RG, Naganathan V, et al. Lifestyle factors, medications, and disease influence bone mineral density in older men: findings from the CHAMP study. Osteoporos Int 2011;22:2421-37.

17 Hill DD, Cauley JA, Bunker $\mathrm{CH}$, et al. Correlates of bone mineral density among postmenopausal women of African Caribbean ancestry: Tobago women's health study. Bone 2008;43:156-61.

18 Dobnig H, Piswanger-Sölkner JC, Obermayer-Pietsch B, et al. Hip and nonvertebral fracture prediction in nursing home patients: role of bone ultrasound and bone marker measurements. J Clin Endocrinol Metab 2007:92:1678-86.

19 Vestergaard P, Rejnmark L, Mosekilde L. Fracture risk associated with the use of morphine and opiates. J Intern Med 2006;260:76-87.

20 Williams LJ, Pasco JA, Henry MJ, et al. Paracetamol (acetaminophen) use, fracture and bone mineral density. Bone 2011;48:1277-81.

21 Vestergaard P, Rejnmark L, Mosekilde L. Fracture risk associated with use of nonsteroidal anti-inflammatory drugs, acetylsalicylic acid, and acetaminophen and the effects of rheumatoid arthritis and osteoarthritis. Calcif Tissue Int 2006;79:84-94.

22 Vestergaard P, Hermann P, Jensen J-EB, et al. Effects of paracetamol, non-steroidal anti-inflammatory drugs, acetylsalicylic acid, and opioids on bone mineral density and risk of fracture: results of the Danish osteoporosis prevention study (DOPS). Osteoporos Int 2012;23:1255-65.

23 Hill DD, Cauley JA, Sheu Y, et al. Correlates of bone mineral density in men of African ancestry: the Tobago bone health study. Osteoporos Int 2008;19:227-34.

24 Bonten TN, de Mutsert R, Rosendaal FR, et al. Chronic use of lowdose aspirin is not associated with lower bone mineral density in the general population. Int J Cardiol 2017;244:298-302.

25 Chuang P-Y, Shen S-H, Yang T-Y, et al. Non-Steroidal antiinflammatory drugs and the risk of a second hip fracture: a propensity-score matching study. BMC Musculoskelet Disord 2016;17:201.

26 Vestergaard P, Steinberg TH, Schwarz P, et al. Use of the oral platelet inhibitors dipyridamole and acetylsalicylic acid is associated with increased risk of fracture. Int $\mathrm{J}$ Cardiol 2012;160:36-40.

27 Chin K-Y. A review on the relationship between aspirin and bone health. J Osteoporos 2017;2017:3710959

28 Anello C, Fleiss JL. Exploratory or analytic meta-analysis: should we distinguish between them? J Clin Epidemiol 1995;48:109-16.

29 Martyn-St James M, Carroll S. Meta-analysis of walking for preservation of bone mineral density in postmenopausal women. Bone 2008;43:521-31.

30 The Joanna Briggs Institute. Joanna Briggs Institute Reviewers' Manual: 2016 Edition. Australia: The Joanna Briggs Institute, 2016.

31 Moola S, Munn Z, Sears K, et al. Conducting systematic reviews of association (etiology): the Joanna Briggs Institute's approach. Int J Evid Based Healthc 2015;13:163-9.

32 Schmidt FL, Hunter JE. Methods of meta-analysis: correcting error and bias in research findings. Sage publications, 2014

33 Higgins JP, Green S. Cochrane Handbook for systematic reviews of interventions. The Cochrane Collaboration, 2011. www.handbook. cochrane.org

34 Deeks JJ, Higgins JP. Statistical algorithms in review manager 5. Statistical Methods Group of The Cochrane Collaboration, 2010.

35 Stroup DF, Berlin JA, Morton SC, et al. Meta-analysis of observational studies in epidemiology: a proposal for reporting. meta-analysis of observational studies in epidemiology (moose) group. JAMA 2000;283:2008-12.

36 Jackson D, Turner R. Power analysis for random-effects metaanalysis. Res Synth Methods 2017;8:290-302.

37 Ryan R. Heterogeneity and subgroup analyses in Cochrane consumers and communication group reviews: planning the analysis at protocol stage. Available: http://cccrg.cochrane.org [Accessed Dec 2016].

38 De Martinis M, Franceschi C, Monti D, et al. Inflammation markers predicting frailty and mortality in the elderly. Exp Mol Pathol 2006;80:219-27.

39 Lane NE, Bauer DC, Nevitt MC, et al. Aspirin and nonsteroidal antiinflammatory drug use in elderly women: effects on a marker of bone resorption. the study of osteoporotic fractures Research Group. J Rheumatol 1997;24:1132-6.

40 Morton DJ, Barrett-Connor EL, Schneider DL. Nonsteroidal antiinflammatory drugs and bone mineral density in older women: the Rancho bernardo study. J Bone Miner Res 1998;13:1924-31.

41 Fang J, George MG, Gindi RM, et al. Use of low-dose aspirin as secondary prevention of atherosclerotic cardiovascular disease in US adults (from the National health interview survey, 2012). Am J Cardiol 2015;115:895-900. 
42 Cuzick J, Otto F, Baron JA, et al. Aspirin and non-steroidal antiinflammatory drugs for cancer prevention: an international consensus statement. Lancet Oncol 2009;10:501-7.

43 Pasco JA, Jacka FN, Williams LJ, et al. Clinical implications of the cytokine hypothesis of depression: the association between use of statins and aspirin and the risk of major depression. Psychother Psychosom 2010;79:323-5.

44 Egger M, Schneider M, Davey Smith G. Spurious precision? Metaanalysis of observational studies. BMJ 1998;316:140-4.

45 Simunovic N, Sprague S, Bhandari M, et al. Methodological issues in systematic reviews and meta-analyses of observational studies in orthopaedic research. J Bone Joint Surg Am 2009;91 Suppl 3:87-94.

46 Farmer KC. Methods for measuring and monitoring medication regimen adherence in clinical trials and clinical practice. Clin Ther 1999;21:1074-90.
47 World Health Organization. Prevention and management of osteoporosis: report of a WHO scientific group. Diamond Pocket Books Ltd, 2003.

48 Odén A, McCloskey EV, Kanis JA, et al. Burden of high fracture probability worldwide: secular increases 2010-2040. Osteoporos Int 2015;26:2243-8.

49 Li L, Geraghty OC, Mehta Z, et al. Age-specific risks, severity, time course, and outcome of bleeding on long-term antiplatelet treatment after vascular events: a population-based cohort study. Lancet 2017;390:490-9.

50 Berger JS, Roncaglioni MC, Avanzini F, et al. Aspirin for the primary prevention of cardiovascular events in women and men: a sexspecific meta-analysis of randomized controlled trials. JAMA 2006;295:306-13.

51 Gorelick PB, Weisman SM. Risk of hemorrhagic stroke with aspirin use: an update. Stroke 2005;36:1801-7. 